\title{
ESTUDO SOBRE SATISFAÇÃO ACADÊMICA NO CURSO DE ADMINISTRAÇÃO EM UMA INSTITUIÇÃO DE ENSINO PÚBLICA
}

\author{
Dalieva Fernandes Costa \\ Universidade Federal de Campina Grande - UFCG. Brasil \\ dalyeva-una@hotmail.com·https://orcid.org/0000-0001-6422-6664 \\ Marcos Macri Olivera \\ Universidade Federal de Campina Grande - UFCG. Brasil \\ macri.ccjs@gmail.com · https://orcid.org/0000-0001-9446-4727 \\ Luma Michelly Soares Rodrigues Macri \\ Universidade do Estado do Rio Grande do Norte - UERN. Brasil \\ lumamichelly@hotmail.com · https://orcid.org/0000-0002-3898-6659 \\ Allan Sarmento Vieira \\ Universidade Federal de Campina Grande - UFCG. Brasil \\ allan.sarmento@ufcg.edu.br·https://orcid.org/0000-0003-2065-0599 \\ Érika Lira da Silva \\ Universidade Federal de Campina Grande - UFCG. Brasil \\ erikaliradasilva@gmail.com · https://orcid.org/0000-0003-2812-6265
}

\begin{abstract}
Resumo. A construção de uma pesquisa de satisfação é importante para o desenvolvimento de um ensino de qualidade. A noção da concepção dos estudantes no que diz respeito à instituição de ensino que escolheram para seguir sua carreira acadêmica é suprimento essencial para a edificação de uma educação superior sólida. O objetivo deste estudo foi investigar os níveis de satisfação dos alunos do Curso de Administração do Centro de Ciências Jurídicas e Sociais da Universidade Federal de Campina Grande (CCJS/UFCG). Para a coleta de dados, foi aplicado, a 134 alunos do referido curso, um questionário composto por 31 questões sobre satisfação, envolvendo diversos aspectos relacionados à vida acadêmica dos estudantes, e cinco opções de satisfação distribuídas em uma escala de satisfeito a totalmente satisfeito. Entre os resultados obtidos, o maior índice de satisfação reside na segurança oferecida pela instituição, com 83\%, e o maior índice de insatisfação, com 40\%, na diversidade das atividades extracurriculares oferecidas. No geral, ficou evidenciado que a satisfação dos acadêmicos desse curso apresenta-se de forma positiva, com alguns pontos a serem aprimorados. Os resultados obtidos por este estudo podem ser úteis à instituição, no sentido de elaborar e implementar melhorias, além de potencializar condutas avaliadas positivamente.
\end{abstract}

Palavras-chave: Satisfação, Ensino Superior, qualidade.

\section{RESEARCH ON ACADEMIC SATISFACTION IN THE ADMINISTRATION IN A PUBLIC EDUCATION INSTITUTION}

\begin{abstract}
Developing a satisfaction survey is important for the development of quality education. The notion of the conception of students in regard to the educational institution they chose to pursue their academic career is an essential condition for the construction of a solid higher education. The objective of this work was to investigate how the state of the satisfaction levels of the students of the Administration Career of the Center of Legal and Social Sciences of the Federal University of Campina Grande (CCJS /
\end{abstract}


UFCG), in the Brazilian state of Paraíba 31 questions about satisfaction were applied, inquiring about various aspects related to the academic life of 134 students of said career. In this questionnaire, a Likert scale was used with five options, which varied between nothing satisfied and totally satisfied. Among the results obtained, the highest satisfaction index is represented by the security offered by the institution, with $83 \%$, and the diversity of extracurricular activities presented the highest index of dissatisfaction, reaching $40 \%$. It was evidenced, therefore, that the satisfaction of the students of this career is shown, in a general way, as positive, paying special attention to some aspects that must be perfected. The results obtained by this study can be useful to the institution, in the sense of elaborating and implementing improvements, and encouraging positively evaluated behaviors.

Keywords: Satisfaction. Higher Education, quality.

\title{
ESTUDIO SOBRE SATISFACCIÓN ACADÉMICA EN LA CARRERA DE ADMINISTRACIÓN EN UNA INSTITUCIÓN DE ENSEÑANZA PÚBLICA
}

\begin{abstract}
Resumen: Elaborar una encuesta de satisfacción es importante para el desarrollo de una enseñanza de calidad. La noción de la concepción de los estudiantes en lo que se refiere a la institución de enseñanza que eligieron para seguir su carrera académica es condición esencial para la edificación de una educación superior sólida. El objetivo de este trabajo fue investigar cómo se caracteriza el estado de los niveles de satisfacción de los alumnos de la carrera de Administración del Centro de Ciencias Jurídicas y Sociales de la Universidad Federal de Campina Grande (CCJS / UFCG), en el estado brasileño de Paraíba. Se aplicaron 31 preguntas sobre satisfacción, indagando sobre diversos aspectos relacionados a la vida académica de 134 estudiantes de dicha carrera. En este cuestionario se utilizó una escala de Likert con cinco opciones, que variaban entre nada satisfecho y totalmente satisfecho. Entre los resultados obtenidos, el mayor índice de satisfacción está representado por la seguridad ofrecida por la institución, con un $83 \%$, y la diversidad de las actividades extracurriculares presentó el mayor índice de insatisfacción, llegando a un $40 \%$. Se evidenció, por lo tanto, que la satisfacción de los estudiantes de esta carrera se muestra, de manera general, como positiva, prestando especial atención a algunos aspectos que deben ser perfeccionados. Los resultados obtenidos por este estudio pueden serle útiles a la institución, en el sentido de elaborar e implementar mejoras, y fomentar conductas evaluadas positivamente.
\end{abstract}

Palabras clave: Satisfacción. Enseñanza Superior, calidad.

\section{Introdução}

É notável o crescimento do número de instituições, cursos e estudantes de nível superior no Brasil. Isso se dá pelo crescimento do número de instituições de ensino superior (IES) da iniciativa privada e pelas facilidades oferecidas pelos programas de inclusão dos estudantes no nível superior, o que reflete uma mudança em todo o cenário nacional, em virtude das emergentes exigências do mercado de trabalho.

No Brasil, o curso de graduação em Administração cresceu com maior ênfase no ano de 2011, quando se encontravam matriculados 858.899 alunos em todo o país, o que representa 13\% dos alunos matriculados nas IES naquele ano. Em 2012, segundo o Censo da Educação Superior realizado pelo INEP/MEC (2012), o curso teve 833.042 matrículas, apesar de ser um número menor do que o do ano anterior, ainda era o curso com mais estudantes no país.

A partir de 2015, houve um declínio no número de matrículas no curso, mas este ainda continuou entre os principais cursos de graduação do Brasil. No ano de 2015, a graduação em Administração ficou em segundo lugar, com 766.859 alunos, perdendo 
apenas para o curso de Direito, com 853.211 alunos, o que equivale a 10,6\% contra 9,6\% do curso de Administração (INEP/MEC, 2015). Em 2016, o curso de Administração contou com 801.936 matrículas, permanecendo em segundo lugar, estando o de Direito ainda em primeiro.

Com os avanços nos estudos da Administração e de sua força no mercado de trabalho, bem como com o grande aumento do número de escolas nessa área, surgem questionamentos sobre a qualidade da prestação de serviço (ensino) pelas IES. Esses questionamentos são sobre a satisfação dos estudantes com o curso ofertado, sua estruturação e demais aspectos que influenciam na imagem que essas instituições transmitem para seus alunos.

Um fator que reforça a importância da satisfação dos alunos é a questão da evasão. O INEP (2015) aponta que o crescimento do número de concluintes é inferior ao número de ingressantes, sendo que apenas 3,9\% concluem a graduação contra 10,2\% que ingressam no Ensino Superior, ou seja, os desistentes somam mais de 5\% dos estudantes que ingressam nas IES. Entre os anos de 2014 e 2015, nota-se uma queda de $-2,6 \%$ no número de estudantes ingressantes na rede pública e $-6,9 \%$ na rede privada. Diante desse aumento da evasão nos cursos superiores, surge a necessidade de averiguar quais fatores estão contribuindo para esse efeito.

A evasão é um problema que veio com o crescimento e a expansão do Ensino Superior no Brasil, uma vez que, à medida que cresce o número de matrículas nas IES, cresce também o número de evasão dos estudantes. Essas evasões são registradas principalmente entre os primeiros meses da graduação, situação que se estende para todos os cursos.

O problema da evasão estudantil é algo preocupante que apresenta reflexos sociais, acadêmicos e econômicos. De acordo com Silva Filho et al. (2007), a evasão nas universidades públicas fica entre $9 \%$ e $15 \%$, enquanto na iniciativa privada esse número é de $26 \%$, sendo que a taxa média no país entre os anos de 2000 e 2005 foi de $22 \%$, revelando predisposição a aumento.

No curso de Administração, essa evasão surpreendeu e, de acordo com o INEP (2012), ultrapassou as perspectivas e chegou a atingir o percentual de $33 \%$ de abandono. Para Schargel e Smink (2002), cinco categorias estão ligadas à evasão, elas são de natureza psicológica, sociológica, organizacional, interacional e econômica. As causas psicológicas estão ligadas às situações particulares de cada pessoa; as causas sociológicas estão relacionadas com o ambiente que está inserido; as causas organizacionais são as de responsabilidade das IES em oferecer aparato e estrutura aos estudantes; as causas interacionais referem-se à conduta do aluno em relação aos fatores interacionais e pessoais; e, por fim, as causas econômicas têm relação com os custos e benefícios envolvidos na questão.

Para Mello e Santos (2013, p. 6), "A Universidade possui um papel relevante na contenção da evasão escolar no ensino superior, pois através da adoção de políticas institucionais ela poderá auxiliar os alunos a concluírem seus estudos”. Sabendo de sua importância na retenção e participação nos índices de evasão, as IES assumem uma posição para tentar inibir esses índices. Para Tigrinho (2008), algumas instituições procuram respostas entre as diversas disciplinas para fazer com que os cursos sejam mais envolventes e que a singularidade de cada indivíduo seja atendida.

A satisfação acadêmica está intimamente relacionada com a qualidade do aprendizado e com o contexto educacional ofertado pelas IES. Ela é entendida como a 
avaliação das experiências agregadas à educação. Segundo Archer (1997, p. 23), "a satisfação é o atendimento ou a eliminação de uma necessidade". É importante ressaltar, porém, que essa é apenas uma ferramenta de auxílio para diagnóstico, não se podendo atribuir a qualidade de um curso com base apenas em satisfação.

O nível de satisfação dos alunos com o curso é um fator importante para o estudo sobre a evasão, pois satisfação e evasão podem estar intimamente interligadas, configurando-se, portanto, como uma das causas. A evasão é uma preocupação das IES, uma vez que gera desperdícios financeiros e pode evidenciar possíveis falhas nos seus sistemas de ensino. Para Schleich (2006), a investigação da satisfação no contexto acadêmico possibilita traçar ações que melhorem a qualidade de ensino e aprendizagem no âmbito estudantil.

Sendo assim, este trabalho tem como problema de pesquisa investigar as características do estado de satisfação acadêmica dos alunos do curso de Administração do Centro de Ciências Jurídicas e Sociais da Universidade Federal de Campina Grande, em Sousa - PB. O estudo buscou avaliar fatores relacionados ao ensino oferecido pela universidade na perspectiva dos alunos, medir o grau de satisfação em relação ao curso e apontar aspectos que impactam na satisfação acadêmica dos discentes.

\section{Metodologia}

A pesquisa teve natureza exploratória e descritiva, buscando realizar um estudo sobre a satisfação acadêmica em relação ao Curso de Administração do CCJS/ UFCG, para detectar as variáveis relacionadas à satisfação dos discentes. Sobre pesquisa exploratória, Gil (2007, p. 41) afirma que "este tipo de pesquisa tem como objetivo proporcionar maior familiaridade com o problema, com vistas a torná-lo mais explícito ou a construir hipóteses". Já a pesquisa descritiva tem por finalidade descrever características de determinada população ou fenômeno, nela são estabelecidas relações entre as variáveis, exigindo do investigador uma série de informações a respeito do que se deseja pesquisar (Triviños, 1987 p. 109).

Esta pesquisa é de caráter qualitativo, pois tem foco subjetivo acerca do objeto estudado, e tem como objetivo entender o comportamento de um grupo estipulado. Também se caracteriza como quantitativa, em que os números são classificados e analisados para serem posteriormente transformados em informações. Aponta-se assim, por meio dos números, determinado comportamento dos indivíduos, para uma melhor interpretação da situação.

O universo desta pesquisa constituiu-se dos alunos do Curso de Administração da UFCG/CCJS, ativos, matriculados (2017.1), que cursavam do $3^{\circ}$ ao $9^{\circ}$ período e que apresentavam frequência nas aulas - os alunos recém-ingressantes foram excluídos do universo por ainda não terem completado, pelo menos, um semestre de curso. Inicialmente, a coordenação do respectivo curso informou (via relatório impresso) que o quantitativo era de 168 alunos. Todavia, depois de cinco tentativas de encontro para a aplicação do instrumento de pesquisa, foi verificado que os alunos ativos eram 134, sendo essa quantidade o valor real do universo desta pesquisa. Questionários foram aplicados a todos esses membros, realizando-se um censo.

Os dados foram coletados por meio desse questionário que contou com 31 questões objetivas - relacionadas a diversos aspectos, como currículo escolar, relação com colegas e professores, didática adotada pelos discentes, adaptação pessoal, 
infraestrutura e serviço prestado pelos servidores da instituição - e uma questão subjetiva - que os alunos eram livres para responder ou não. Esse questionário foi adaptado da dissertação de mestrado "Integração na Educação Superior e satisfação acadêmica de estudantes ingressantes e concluintes", de Ana Lúcia Righi Schleich (2006).

O questionário foi aplicado no mês de julho de 2017, durante três semanas. Foram utilizadas escalas de Likert para verificar a opinião dos respondentes, com cinco opções para os alunos, com níveis entre nada satisfeito e totalmente satisfeito. A análise e interpretação dos dados ocorreram de acordo com o embasamento teórico existente neste estudo.

\section{Resultados e discussão}

Os resultados aqui apresentados foram divididos em três tópicos, iniciando pela apresentação dos entrevistados, por meio de um breve perfil dos estudantes. Posteriormente, são tratadas as questões relacionadas à satisfação acadêmica, à percepção sobre aspectos pedagógicos, experiências em sala de aula, questões físicas e de estrutura, serviços prestados e apoio dado pela instituição.

\section{Perfil dos estudantes}

Inicialmente, tornou-se relevante conhecer algumas características dos alunos participantes da pesquisa. Para isso, eles foram questionados quanto à idade, e os dados apontaram que os estudantes do curso de Administração do CCJS/UFCG têm entre 18 e 24 anos (55,96\% do total de estudantes deste curso), revelando o interesse da juventude pelo curso e dando um aspecto jovem para a profissão.

Quanto ao gênero dos alunos, 61\% são homens e 39\% são mulheres. Essa preferência masculina pela profissão é confirmada por dados de uma pesquisa realizada pelo Conselho Federal de Administração em 2015, revelando que a maioria dos profissionais de administração no Brasil é do sexo masculino, casado e com dependentes. Mesmo com o crescimento feminino na profissão, que passou de $21 \% \mathrm{em}$ 1994 para 34\% em 2015, o sexo masculino ainda prevalece (Conselho Federal de Administração, 2017).

Foi verificado também o semestre em que os alunos ingressaram no curso, entre 2009 e 2016, mostrando que ainda existem alunos da primeira turma de Administração do CCJS, ingressantes no semestre 2009.1 até os ingressantes de 2016.1, visto que os ingressantes 2017.1 não entraram no universo desta pesquisa. A maior parte dos respondentes ingressou em 2016.1, correspondente a 38,28\%. Investigou-se qual o desejo dos alunos ao permanecer no curso, considerando todos os aspectos que envolvem a vida acadêmica dos discentes. Dos 134 respondentes, apenas 2 não pretendem concluí-lo, revelando um percentual baixíssimo de apenas $1 \%$ contra os $99 \%$ que pretendem continuar no curso.

A maior parte dos alunos, 74\%, trabalha e possui experiências profissionais, sendo esse um percentual relevante de acadêmicos inseridos no mercado de trabalho. Quanto às áreas de atuação, os resultados foram bastante diversificados. Dentre as respostas, destacaram-se: auxiliares administrativos, 12,64\%; funcionários públicos, 9,20\%; vendedores, 9,20\%; e gerentes, 6,90\%. Esse aspecto é de grande relevância, 
visto que experiências de mercado são relevantes para a formação e para as atividades exercidas pelo profissional da Administração.

Foi abordado também o tempo que os alunos dedicam as suas atividades profissionais, importante aspecto a ser considerado, no tocante às exigências de prazos de entrega de atividades. Constatou-se que $65 \%$ trabalham em tempo integral, o que muitas vezes interfere no rendimento acadêmico de alguns alunos. Investigou-se também a quantidade de horas trabalhadas por semana, e os resultados apontaram que $29,29 \%$ dos alunos têm uma jornada de 44 horas trabalhadas semanalmente, um fator importante que compromete o rendimento acadêmico. Sendo assim, esse fator apresenta-se como um desafio para os estudantes conciliarem seu tempo e se dividirem entre trabalho e estudo, visto que devem cumprir com suas responsabilidades em ambos os âmbitos.

Portanto, a maioria dos estudantes participantes da pesquisa é homem, entre 18 e 24 anos, ingressante em 2016, que trabalha e possui experiências profissionais em diversas áreas, trabalha em tempo integral com jornada entre 40 a 44 horas semanais.

\section{Percepção quanto aos aspectos pedagógicos e ao convívio em sala de aula}

Para entender como os discentes em questão percebem em termos de satisfação ou insatisfação seu convívio em sala de aula, relacionamento com colegas e professores, bem como aspectos referentes às questões pedagógicas, foram feitos questionamentos para compreender sua opinião. A Tabela 1 traz uma síntese dos percentuais de respostas para esse tópico.

Tabela 1

Satisfação quanto aos aspectos pedagógicos e ao convívio em sala de aula

\begin{tabular}{|c|c|c|c|c|c|}
\hline \multirow[b]{2}{*}{ Variáveis analisadas } & \multicolumn{5}{|c|}{ NÍVEL DE SATISFAÇÃO (\%) } \\
\hline & \multicolumn{2}{|c|}{ Nada satisfeito } & \multicolumn{3}{|c|}{ Totalmente satisfeito } \\
\hline 1. Currículo do curso & $1 \%$ & $5 \%$ & $31 \%$ & $51 \%$ & $12 \%$ \\
\hline 2. Recursos audiovisuais, de informática e softwares & $1 \%$ & $12 \%$ & $33 \%$ & $39 \%$ & $15 \%$ \\
\hline 4. Envolvimento pessoal nas atividades do curso & $1 \%$ & $15 \%$ & $40 \%$ & $34 \%$ & $10 \%$ \\
\hline 5. Adequação do conteúdo do curso à formação & $0 \%$ & $5 \%$ & $37 \%$ & $43 \%$ & $15 \%$ \\
\hline 6. Relacionamento com os colegas & $1 \%$ & $3 \%$ & $14 \%$ & $37 \%$ & $45 \%$ \\
\hline $\begin{array}{l}\text { 9. Conhecimento dos professores sobre o conteúdo das disciplinas que } \\
\text { ministram }\end{array}$ & $0 \%$ & $2 \%$ & $25 \%$ & $47 \%$ & $26 \%$ \\
\hline 10. Avaliação proposta pelos professores & $1 \%$ & $8 \%$ & $30 \%$ & $48 \%$ & $13 \%$ \\
\hline $\begin{array}{l}\text { 11. Disponibilidade dos professores em atender os alunos fora da sala de } \\
\text { aula }\end{array}$ & $3 \%$ & $13 \%$ & $33 \%$ & $32 \%$ & $19 \%$ \\
\hline $\begin{array}{l}\text { 12. Adequação entre as tarefas exigidas no curso e o tempo estabelecido } \\
\text { pelos professores para realização }\end{array}$ & $0 \%$ & $12 \%$ & $40 \%$ & $40 \%$ & $8 \%$ \\
\hline $\begin{array}{l}\text { 13. Reconhecimento, por parte dos professores, do envolvimento do aluno } \\
\text { com a formação }\end{array}$ & $2 \%$ & $7 \%$ & $42 \%$ & $38 \%$ & $11 \%$ \\
\hline 14. Estratégia de aula utilizada pelos professores & $0 \%$ & $9 \%$ & $34 \%$ & $44 \%$ & $13 \%$ \\
\hline
\end{tabular}

Nota: Fonte: Dados da pesquisa (2017). 
Como é possível observar na Tabela 1, no item currículo do curso, abordou-se a satisfação dos alunos acerca das disciplinas básicas, instrumentais e disciplinas da formação profissional da administração, 63\% consideraram-se satisfeitos e muito satisfeitos, com apenas $6 \%$ de insatisfação.

Investigou-se também a opinião dos estudantes em relação à adequação do conteúdo do curso à formação, uma vez que essa adequação contribui para uma melhor qualidade do aprendizado, necessária para uma boa qualificação profissional. A Tabela 1 mostra resultados positivos, com 58\% (considerando satisfeitos e muito satisfeitos) nos níveis de satisfação dos alunos.

Em se tratando do envolvimento pessoal no curso e do desempenho obtido, perguntou-se sobre a percepção dos estudantes. Das respostas, 57\% afirmaram estar satisfeitos e muito satisfeitos, contra apenas $7 \%$ de insatisfeitos. Também se indagou sobre os níveis de satisfação quanto ao envolvimento pessoal nas atividades do curso, considerando que é de responsabilidade do aluno o interesse com seu desempenho no curso. No período de graduação, é demandada autonomia dos acadêmicos para que participem das atividades curriculares e extracurriculares, como palestras, cursos, congressos e outros. Como resultado, $44 \%$ se dizem satisfeitos e envolvidos com essas atividades, e outros $40 \%$ posicionaram-se de forma neutra nesse aspecto.

Investigou-se o nível de satisfação dos alunos sobre a relevância do conteúdo das disciplinas, considerando a importância desses conteúdos para a formação profissional. Os critérios de relevância dos conteúdos das disciplinas são os considerados primordiais (as disciplinas específicas da área) para se alcançar os resultados desejados na formação acadêmica. Os alunos do CCJS consideram satisfatória, com $61 \%$ (considerando satisfeitos e muito satisfeitos), a importância desses conteúdos para sua formação acadêmica.

Em seguida, investigou-se a satisfação dos alunos em relação aos recursos e equipamentos audiovisuais disponíveis na instituição, bem como softwares. Os alunos mostraram-se satisfeitos quanto a isso, seus níveis de satisfação totalizaram 54\%, e apenas $1 \%$ dos acadêmicos revelaram-se nada satisfeitos.

Sobre o nível de satisfação dos alunos considerando o relacionamento direto com os colegas de curso, os alunos apresentaram níveis satisfatórios, totalizando $82 \%$, somando satisfeitos e muito satisfeitos. As relações interpessoais nesse âmbito precisam ser saudáveis com o propósito de que os alunos vejam a instituição de ensino como um ambiente agradável, a fim de evitar conflitos entre si, facilitando assim o processo de aprendizagem.

Quanto ao relacionamento direto com os professores da instituição, o que se pode observar, a partir dos dados da Tabela 1, é um resultado positivo, visto que $75 \%$ dos alunos se consideram satisfeitos e muito satisfeitos, revelando um bom relacionamento entre discentes e docentes. É de muita importância uma interação positiva para que se obtenha o sucesso no processo ensino-aprendizagem. Portanto, a satisfação dos discentes com a atuação dos docentes aponta que o comportamento, o envolvimento, as estratégias de pensamento e o grau de esforço desses profissionais correspondem ao esperado pelos alunos.

Sobre a satisfação dos alunos em relação ao interesse dos professores em atendelos durante as aulas, considerando suas expectativas e necessidades - sabendo que o olhar do professor para o aluno é fundamental para a construção e o sucesso da sua 
aprendizagem -, 74\% (considerando satisfeitos e muito satisfeitos) dos estudantes disseram estar satisfeitos com a postura adotada pelos professores nesse sentido. Também se perguntou sobre a disponibilidade dos professores em atender os alunos fora da sala de aula. De acordo com a Tabela 1, 51\% (considerando satisfeitos e muito satisfeitos) dos alunos estão satisfeitos com a disponibilidade dos professores em atendê-los fora da sala de aula, momentos em que os professores precisam estar aptos para responder às necessidades diferenciadas de seus alunos.

Abordaram-se também as opiniões dos alunos sobre o conhecimento dos professores acerca do conteúdo das disciplinas que ministram, considerando a relevância dos assuntos expostos em sala de aula pelo professor. Das respostas, $73 \%$ dos alunos estão satisfeitos (considerando satisfeitos e muito satisfeitos) com o conhecimento apresentado pelos docentes. Com relação às estratégias de aula utilizadas pelos professores, que devem contribuir com a construção do conhecimento, de acordo com as experiências pessoais de cada aluno, e devem facilitar o entendimento e melhorar o processo de aprendizagem, o resultado obtivo foi positivo, com 57\% (considerando satisfeitos e muito satisfeitos) de satisfação dos estudantes.

A seguir, investigou-se a opinião dos discentes quanto à adequação entre as tarefas exigidas no curso e o tempo estabelecido pelos professores para realização destas. Mesmo apresentando resultados positivos, com $48 \%$ de satisfação (considerando satisfeitos e muito satisfeitos) dos alunos, ainda existem relatos de que esse prazo é muito curto, principalmente para os que trabalham em tempo integral, o que explica o percentual de $40 \%$ de neutralidade nessa questão.

Sobre os níveis de satisfação dos alunos para a questão de avaliação proposta pelos professores, os alunos apresentaram $61 \%$ (considerando satisfeitos e muito satisfeitos) de satisfação. A avaliação de desempenho frequentemente tem sido empregada nas Instituições de Ensino Superior como ferramenta para analisar o nível de satisfação dos estudantes, e assim averiguar a proposta de avaliação imposta pelos professores, na tentativa de potencializar a eficiência desse instrumento.

Perguntou-se ainda, dentro do aspecto das experiências em sala de aula, como os alunos se sentem a respeito do reconhecimento, por parte dos professores, dos esforços dos graduandos na sua formação. Na visão dos alunos, os professores do CCJS possuem postura satisfatória, com $49 \%$ (considerando satisfeitos e muito satisfeitos) de aprovação. Mas, é importante ressaltar que $42 \%$ demonstraram neutralidade, evidenciando que alguns alunos não se sentem envolvidos e valorizados pelo modo como os professores enxergam seu desempenho. Os educadores, de modo geral, têm papel de grande relevância na formação dos alunos, para isso é preciso que vejam não apenas as dificuldades e limitações dos alunos, mas também suas competências a fim de estimular o aprendizado.

\section{Percepção sobre infraestrutura, serviços prestados e apoio dado aos alunos}

Nesse tópico, são abordados os dados obtidos sobre a infraestrutura, os serviços prestados nos principais setores que compõem a instituição abordada, bem como o apoio dado aos alunos, na busca de uma formação de qualidade e posterior inserção no mercado de trabalho. A Tabela 2 a seguir expõe os percentuais para cada item pesquisado. 
Tabela 2

Satisfação quanto aos aspectos físicos, serviços prestados e ao apoio dado pela instituição

\begin{tabular}{|c|c|c|c|c|c|}
\hline \multirow{3}{*}{ Variáveis analisadas } & \multicolumn{5}{|c|}{ NÍVEL DE SATISFAÇÃO } \\
\hline & \multicolumn{2}{|c|}{ Nada satisfeito } & \multicolumn{3}{|c|}{ Totalmente satisfeito } \\
\hline & 1 & 2 & 3 & 4 & 5 \\
\hline 1. Infraestrutura física da instituição & $2 \%$ & $2 \%$ & $20 \%$ & $39 \%$ & $37 \%$ \\
\hline 2. Conforto das instalações da instituição & $1 \%$ & $8 \%$ & $28 \%$ & $39 \%$ & $24 \%$ \\
\hline 3. Localização dos diferentes setores que compõem a instituição & $10 \%$ & $12 \%$ & $39 \%$ & $39 \%$ & $10 \%$ \\
\hline $\begin{array}{l}\text { 4. Atendimento e clareza das informações oferecidas pelos } \\
\text { funcionários da secretaria }\end{array}$ & $6 \%$ & $14 \%$ & $34 \%$ & $35 \%$ & $11 \%$ \\
\hline $\begin{array}{l}\text { 5. Atendimento e clareza das informações oferecidas pelos } \\
\text { funcionários da biblioteca }\end{array}$ & $3 \%$ & $11 \%$ & $29 \%$ & $43 \%$ & $14 \%$ \\
\hline 6. Serviços oferecidos pela biblioteca & $0 \%$ & $5 \%$ & $31 \%$ & $41 \%$ & $23 \%$ \\
\hline 7. Acervo disponível na biblioteca & $4 \%$ & $7 \%$ & $22 \%$ & $45 \%$ & $22 \%$ \\
\hline 8. Limpeza da instituição & $0 \%$ & $5 \%$ & $15 \%$ & $38 \%$ & $42 \%$ \\
\hline 9. Segurança oferecida pela instituição (portaria, seguranças) & $0 \%$ & $4 \%$ & $13 \%$ & $37 \%$ & $43 \%$ \\
\hline 10. Eventos sociais oferecidos pela instituição & $9 \%$ & $23 \%$ & $36 \%$ & $28 \%$ & $4 \%$ \\
\hline $\begin{array}{l}\text { 11. Diversidade das atividades extracurriculares oferecidas pela } \\
\text { instituição }\end{array}$ & $4 \%$ & $7 \%$ & $33 \%$ & $43 \%$ & $13 \%$ \\
\hline $\begin{array}{l}\text { 12. Programas ou serviços de apoio aos estudantes oferecidos } \\
\text { pela instituição }\end{array}$ & $3 \%$ & $22 \%$ & $42 \%$ & $30 \%$ & $3 \%$ \\
\hline $\begin{array}{l}\text { 13. Condições oferecidas para o desenvolvimento profissional } \\
\text { dos alunos }\end{array}$ & $2 \%$ & $15 \%$ & $46 \%$ & $33 \%$ & $4 \%$ \\
\hline 14. Compromisso da instituição com a qualidade de formação & $1 \%$ & $3 \%$ & $27 \%$ & $46 \%$ & $23 \%$ \\
\hline $\begin{array}{l}\text { 15.Condições para o ingresso na área profissional de formação } \\
\text { (estratégias de inserção e contato com mundo do trabalho) }\end{array}$ & $11 \%$ & $11 \%$ & $47 \%$ & $26 \%$ & $5 \%$ \\
\hline $\begin{array}{l}\text { 16. Oportunidade de desenvolvimento pessoal oferecida pela } \\
\text { instituição }\end{array}$ & $1 \%$ & $9 \%$ & $42 \%$ & $39 \%$ & $9 \%$ \\
\hline
\end{tabular}

Nota: Fonte: Dados da pesquisa (2017).

Inicialmente, questionou-se sobre a satisfação relacionada à infraestrutura física, considerando todas as instalações dos setores da instituição. Infraestrutura física é um dos núcleos essenciais em volta dos quais se formam as condições da qualidade acadêmica das universidades. Desse modo, em relação ao CCJS, os estudantes mostraram-se favoráveis, como mostra a Tabela 2 , com $76 \%$ de satisfação (considerando satisfeitos e muito satisfeitos). A seguir, questionou-se sobre o conforto das instalações. Com índice de $63 \%$ de satisfação, somando-se satisfeitos e muito satisfeitos, o conforto das instalações da instituição apresenta um importante fator que influencia na qualidade do aprendizado e da prestação de serviço pelos servidores.

Investigou-se o nível de satisfação dos alunos com relação à localização dos diferentes setores que compõem a instituição, analisando a facilidade de locomoção dentro do campus universitário. Nesse contexto, os alunos se mostraram divididos, com $39 \%$ mostrando-se imparciais e 39\% dizendo-se satisfeitos (considerando satisfeitos e muito satisfeitos).

Questionou-se o nível de satisfação dos alunos em relação ao atendimento e à clareza das informações oferecidas pelos funcionários da secretaria, bem como em relação à qualidade do serviço oferecido por esse setor, e $46 \%$ consideram-se satisfeitos e muito satisfeitos. A secretaria é um setor de grande importância na instituição, e a qualidade desse serviço precisa ser uma constante a fim de ajudar não só os alunos, mas todos que dele necessitam. 
Abordou-se também o atendimento oferecido pelos funcionários da biblioteca. Os estudantes mostraram-se satisfeitos, com o percentual de 57\%. Em relação aos serviços oferecidos pela biblioteca, $64 \%$ consideraram-se satisfeitos e muito satisfeitos. Para o requisito acervo disponível na biblioteca, $67 \%$ apresentaram índice satisfatório. Para Campos e Nascimento (2012, p. 3), "a biblioteca universitária é um centro de informação que deve estar engajado com a missão da instituição, oferecendo a seus usuários os diferentes suportes informacionais necessários ao trinômio ensino, pesquisa e extensão".

Outro aspecto investigado dentro dos serviços ofertados pela instituição foi a segurança (portaria, seguranças). Sendo um serviço de necessidade básica e direito de todos os cidadãos, ele oferece tranquilidade a todos os alunos e servidores. De acordo com os resultados, a segurança prestada ao CCJS é avaliada de forma positiva pelos alunos, com $83 \%$ de satisfação (considerando satisfeitos e muito satisfeitos).

Analisou-se também a satisfação em relação à limpeza da instituição, que é de fundamental importância para se garantir bem-estar de todos os que fazem uso das instalações. Os alunos atribuíram valores satisfatórios, com 80\% (considerando satisfeitos e muito satisfeitos) de satisfação.

Já em relação aos eventos sociais oferecidos pelo centro universitário, os alunos mostraram-se divididos, a maioria, $36 \%$, teve um posicionamento neutro. Sabendo-se da importância desses eventos para a carreira profissional dos alunos, a instituição poderia investir mais em eventos acadêmicos.

Perguntou-se também sobre a diversidade das atividades extracurriculares que a instituição oferece aos alunos. Os dados apontam que a maioria dos alunos, 43\%, está em posição de neutralidade; $7 \%$ apresentam insatisfação; $33 \%$ um nível muito baixo de satisfação. Apenas 4\% consideram-se satisfeitos. Sabe-se que as atividades extracurriculares podem contribuir para a adaptação acadêmica dos alunos envolvidos com elas (Teixeira et al., 2008).

Quanto aos programas ou serviços de apoio financeiro disponibilizados pela instituição, 33\% dos alunos se dizem satisfeitos (considerando satisfeitos e muito satisfeitos) com o apoio que recebem. Porém, a maioria deles se posiciona de forma neutra, com o percentual de $42 \%$, uma vez que muitos não têm conhecimento exato de como adquirir esses apoios.

Foram averiguados também os níveis de satisfação relacionados às condições oferecidas para o desenvolvimento profissional (conhecimento e habilidades para a atuação) dos alunos, considerando as oportunidades que estes recebem para se desenvolver profissionalmente. A maioria dos respondentes mostrou-se neutra, com $46 \%$, e $34 \%$ consideraram-se satisfeitos e muito satisfeitos.

Considerando o papel da instituição na formação cidadã e profissional, investigou-se os níveis de satisfação dos acadêmicos quanto ao compromisso da instituição com a qualidade de formação. Dos alunos, 69\% sentem-se satisfeitos com o compromisso da instituição.

Sobre as condições para o ingresso na área profissional de formação (estratégias de inserção e contato com o mundo do trabalho), apenas $31 \%$ (considerando satisfeitos e muito satisfeitos) dos acadêmicos se dizem satisfeitos, ou seja, menos da metade. Esse é um requisito que pode, então, ser melhorado. 
Investigou-se também o nível de satisfação dos estudantes em relação às oportunidades de desenvolvimento pessoal proporcionadas pela instituição. Observouse que $48 \%$ dos respondentes sentem-se satisfeitos (considerando satisfeitos e muito satisfeitos) com o que a instituição oferece para os alunos, estimulando a busca por habilidades e competências necessárias para o exercício profissional e desenvolvimento pessoal.

Sobre outras informações relevantes a respeito da (in)satisfação com a experiência acadêmica atual, foram feitos alguns relatos, havendo comentários negativos por parte de alguns estudantes, por diversos motivos, demonstrando assim grande insatisfação. Por outro lado, houve relatos de grande satisfação com o curso, evidenciando a diversidade de opiniões.

\section{Conclusões}

O presente estudo teve como objetivo investigar características do estado de satisfação dos alunos do curso de Administração da UFCG/CCJS. De maneira mais específica, o estudo buscou avaliar os fatores relacionados ao ensino oferecido pela universidade na perspectiva dos alunos, medir o grau de satisfação dos graduandos em relação ao curso de Administração e, por último, apontar aspectos que impactam na satisfação acadêmica dos discentes do curso.

O perfil dos estudantes participantes da pesquisa consistiu, em sua maioria, de homens, entre 18 e 24 anos, ingressantes em 2016, que trabalham em tempo integral e possuem experiências profissionais em diversas áreas.

Quanto aos índices de satisfação, grande parte das variáveis estudadas apresentou valores positivos, acima de 50\%, considerando satisfeitos e muito satisfeitos. Desse modo, os maiores percentuais observados foram: relacionamento com os professores, com 75\%; relacionamento com os colegas do curso, com 82\%; interesse dos professores em atender os estudantes durante as aulas, com 74\%; conhecimento dos professores sobre o conteúdo das disciplinas que ministram, com 73\%; segurança oferecida pela instituição (portaria, seguranças), com 83\%; infraestrutura física das salas de aula, com 76\%; infraestrutura física da instituição, com 76\%; e limpeza da instituição, com 80\%. Assim, o maior percentual de satisfação dos acadêmicos é relacionado à segurança da instituição.

As outras variáveis que obtiveram valores positivos para os níveis de satisfação, porém menores que 50\%, foram: programas ou serviços de apoio oferecidos aos estudantes pela instituição, com 33\%; condições para ingresso na área profissional de formação (estratégias de inserção e contato com o mundo do trabalho), com $31 \%$; programa de apoio financeiro oferecido pela instituição, com 33\%. Já a diversidade das atividades extracurriculares oferecidas pela instituição apresentou o menor índice de satisfação, com $16 \%$.

Quanto aos níveis de insatisfação, considerando nada satisfeito e pouco satisfeito, eles obtiveram resultados acima de $20 \%$ nos seguintes quesitos: diversidade das atividades extracurriculares oferecidas pela instituição, que apresentou o maior índice, com $40 \%$ de insatisfação; eventos sociais oferecidos pela instituição, com 32\%; programas ou serviços de apoio oferecidos aos estudantes pela instituição, com 25\%; equipamentos e softwares oferecidos pelo laboratório de informática, com 29\%; e localização dos diferentes setores que compõem a instituição, com $22 \%$. 
Entre $10 \%$ e $20 \%$ de insatisfação, temos os seguintes aspectos: recursos e equipamentos audiovisuais disponíveis na instituição; atendimento e clareza das informações oferecidas pelos funcionários da secretaria; envolvimento pessoal nas atividades do curso; condições oferecidas para o desenvolvimento profissional (conhecimento e habilidades para a atuação); atendimento e clareza das informações oferecidas pelos funcionários da biblioteca; condições para ingresso na área profissional de formação (estratégias de inserção e contato com mundo do trabalho); acervo disponível na biblioteca; programa de apoio financeiro oferecido pela instituição; oportunidade de desenvolvimento pessoal oferecida pela instituição; disponibilidade dos professores em atender os alunos fora da sala de aula; adequação entre as tarefas exigidas no curso e o tempo estabelecido pelos professores para sua realização. Os demais aspectos obtiveram resultados menores que $10 \%$ para os níveis de insatisfação.

Diante do exposto, é notável que o nível de satisfação dos acadêmicos de Administração do CCJS/UFCG relacionado ao curso e a todos os aspectos que o envolvem é considerado positivo, visto que a maioria dos resultados obteve níveis de satisfação favoráveis. Ainda assim, a instituição deve ter um olhar mais crítico e cauteloso para manter essa satisfação e potencializá-la. Quanto aos aspectos que apresentaram maiores índices de insatisfação, é necessário buscar formas de corrigir possíveis falhas e melhorar constantemente, a fim de superar esses resultados e, assim, oferecer um curso com mais qualidade, que apresente alto grau de aceitabilidade e satisfação.

Assim, ficam abertos os caminhos para futuros estudos voltados para a pesquisa sobre satisfação estudantil acadêmica, e auxiliar na melhoria da qualidade do ensino oferecido pelas instituições.

\section{Referências}

Archer, E. R. (1997) Mito da motivação. In C. W. BERGAMINI, R. CODA. Psicodinâmica da vida organizacional: motivação e liderança (pp. 23-46). São Paulo: Atlas.

Campos, D. F. e Nascimento, M. do S. (2012). Qualidade do serviço em bibliotecas universitárias: percepção dos usuários em contextos público e privado. Retrieved from https://periodicos.sbu.unicamp.br/ojs/index.php/rdbci/article/view/1619/pdf 57.

Cavalli, A. (1996). Per una ricomposizione tra qualitá e quantitá. In C. Cipolla e A. De Lillo (Orgs.). Il Sociologo e le Sirene: la Sfida dei Metodi Qualitativi. Angeli: Milão.

Centro de Ciências Jurídicas e Sociais. (s.d.). Graduação - Administração. Campus de Sousa - Centro de Ciências Jurídicas e Sociais. Retrieved from http://www.ccjs.ufcg.edu.br/Paginas/Cursos/Graduacao.php?Curso=1.

Conselho Federal de Administração. (2017). História da Administração. Conselho Federal de Administração. Notas Estatísticas Censo da Educação Superior. Retrieved from https://cfa.org.br/administracao-administracao/administracaohistoria-da-profissao/.

Gil, A. C. 2007.Como elaborar projetos de pesquisa. (4. ed.). São Paulo: Atlas. 
Instituto Nacional de Estudos e Pesquisas Educacionais Anísio Teixeira (INEP). (2011). Resumos Técnicos. Retrieved from http://inep.gov.br/web/guest/resumostecnicos1.

Instituto Nacional de Estudos e Pesquisas Educacionais Anísio Teixeira (INEP). (2012). Notas Estatísticas Censo da Educação Superior 2012. Retrieved from http://portal.inep.gov.br/web/guest/educacao-superior.

Instituto Nacional de Estudos e Pesquisas Educacionais Anísio Teixeira (INEP). (2015). Notas Estatísticas Censo da Educação Superior. Ministério da Educação. Retrieved from http://download.inep.gov.br/educacao_superior/censo_superior/documentos/201 5/notas_sobre_o_censo_da_educacao_superior_2014.pdf.

Mainardes, E. W. e Domingues, M. J. C. de S. (2010). Satisfação de estudantes em administração de Joinville/SC. Revista Pensamento Contemporâneo em Administração, 4(2), 76-94. $\quad$ Retrieved from https://www.google.com.br/search?q=SATISFA\%C3\%87\%C3\%83O+DE+EST UDANTES+EM+ADMINISTRA\%C3\%87\%C3\%83O+DE+JOINVILLE/SC\&i e=utf-8\&oe=utf-8\&client=firefox-bab\&gws_rd=cr\&ei=q2e8WJKTE4KawgTilK74DQ.

Mello, S. P. T. e Santos, E. G. (2013). O fenômeno evasão nos cursos superiores de tecnologia: um estudo de caso em uma universidade pública no sul do Brasil, 2013 http://xxiiienangrad.enangrad.org.br/anaisenangrad/_resources/media/artigos/adp /17.pdf.

Gerhardt, T. E. e Silveira, D. T. (Orgs.). (2009). Planejamento e Gestão para o Desenvolvimento Rural da SEAD/UFRGS. Porto Alegre: Editora da UFRGS. Retrieved from http://www.ufrgs.br/cursopgdr/downloadsSerie/derad005.pdf.

Palacio, A. B., Meneses, G. D. e Pérez, P. J. P. (2002). The configuration of the university image and is relationship with satisfaction of students. Journal of Educational Administration, 40(5), 486-505.

Schargel, F. P., e Smink, J. Estratégia para auxiliar o problema de evasão escolar. Rio de Janeiro: Dunya, 2002.

Schleich, A. L. R. (2006). Integração na educação superior e satisfação acadêmica de estudantes ingressantes e concluintes. Dissertação de mestrado. Universidade Estadual de Campinas.

Silva Filho, R. L. L. et al. (2007). A evasão no ensino superior brasileiro. Caderno de Pesquisa, 37(132). Retrieved from http://www.scielo.br/pdf/cp/v37n132/a0737132.pdf

Silva, W. R. da, Brandão Junior, R. D., Souto, J. V. e Silva Junior, N. A. da. (2005). Escolha do curso de administração: uma análise comparativa entre uma instituição pública e uma instituição privada. In Encontro Nacional dos Programas de Pós-Graduação em Administração, 29, Brasília. Anais... Brasília: XXIX ENANPAD.

Teixeira, M. A. P., Dias, A. C. G., Wottrich, S. H., \& Oliveira, A. M. (2008). Adaptação à universidade em jovens calouros. Revista Semestral da Associação Brasileira de Psicologia Escolar e Educacional, 12(1), 185-202. 
Tigrinho, L. M. V. (2008). Evasão escolar nas instituições de ensino superior. Revista

http://www.gestaouniversitaria.com.br/artigos/evasao-escolar-nas-instituicoesde-ensino-superior.

Triviños, A. N. S. (1987). Introdução à pesquisa em ciências sociais: A pesquisa qualitativa em educação. São Paulo: Atlas.

Speller, P., Robl, F. e Meneghel, S. M. (2012). Desafios e perspectivas da educação superior brasileira para a próxima década 2011-2020. Brasília: UNESCO, CNE, MEC. Retrieved from http://unesdoc.unesco.org/images/0021/002189/218964POR.pdf.

Universidade Federal do Amazonas - UFAM. (s. d.). Retrospectiva da Avaliação da UFAM. Comissão Permanente de Avaliação. Retrieved from http://www.cpa.ufam.edu.br/projeto-de-avaliacao/12-retrospectiva-da-avaliacaoda-ufam.html.

Data de recepção: $15 / 02 / 2019$

Data de revisão: $27 / 06 / 2019$

Data do aceite: 28/06/2019 